\title{
Analysis on the Protection of Genetic Resources from the Perspective of Intellectual Property
}

\author{
Xuanyu Chen \\ Law School, Beijing Normal University, Beijing, China \\ Email:201831040014@mail.bnu.edu.cn
}

How to cite this paper: Chen, X. Y. (2019). Analysis on the Protection of Genetic Resources from the Perspective of Intellectual Property. Advances in Applied Sociology, 9, 163-178.

https://doi.org/10.4236/aasoci.2019.96014

Received: April 22, 2019

Accepted: June 10, 2019

Published: June 13, 2019

Copyright $\odot 2019$ by author(s) and Scientific Research Publishing Inc. This work is licensed under the Creative Commons Attribution International License (CC BY 4.0).

http://creativecommons.org/licenses/by/4.0/

\begin{abstract}
Considering the frequent plagiarism and plunder of genetic resources in China, the analysis of genetic resources protection has become a very important issue. This paper used literature analysis method to discuss the protection of genetic resources from the perspective of intellectual property protection. This paper reviewed current practices and policies on intellectual property, and access to genetic resources, in an attempt to better understand the nature of genetic resources and the difficulties of intellectual property protection, expound theoretical framework of genetic resource protection, so as to propose corresponding improvement suggestions under the context of China.
\end{abstract}

\section{Keywords}

Genetic Resources, Intellectual Property Protection, Information Disclosure

\section{Background}

The rise of the fourth industrial revolution marked by the development of biotechnology and the booming of the bio-industry evokes human desires of acquiring and developing biological genetic resources and related traditional knowledge, as well as gain business benefits by adopting modern intellectual property systems such as patents, trade secrets, plant variety rights, etc. Genetic resources are a natural or social wealth on the planet. Human beings have gained enormous economic benefits from the public access to genetic resources in the form of food, medicine and industrial products (OECD, 1996). China has abundant genetic resources, which can be regarded as strategic resources. However, in recent years, due to the limited level of biotechnology, there have been frequent incidents of "plagiarism" and "abuse" in the fields of acquisition, development and utilization of biological genetic resources and related traditional knowledge in China. "As of 2009, 23 of these plants were applied for patents at 
home and abroad by foreign institutions or individuals or applied for patents abroad by domestic institutions. There are nearly 158 patents related to these 23 plants, and these 158 patents have been applied for 588 countries by different countries in the world" (Wu, Xue, Zhao, \& Wang, 2013). Due to the underdevelopment of biotechnology, China's own positioning is a provider of genetic resources. China has joined The Convention on Biological Diversity (CBD), Bonn Guidelines on Access to Genetic Resources and Fair and Equitable Sharing of the Benefits Arising out of their Utilization, and became a party to The Nagoya Protocol in September 2016 (Wei, 2014). The entry into force of The Nagoya Protocol marks the entry into the real implementation phase of the Biological Genetic Resources Access and Benefit-sharing provisions, and China's accession to The Nagoya Protocol marks China's integration into the new international rules on access and benefit-sharing of biological genetic resources ( $\mathrm{Wu}, 2016 \mathrm{a})$.

The intellectual property system is closely related to the acquisition and protection of genetic resources. Intellectual property review is widely used in the defensive protection of genetic resources. In order to negotiate with developed countries equally so as to avoid the loss of resources, Chinese government should first improve the protection by legislation. But, there are some drawbacks in the protection of genetic resources in China. There is no special and unified competent authority in China that is responsible for the protection of domestic genetic resources. It is difficult to coordinate and unify the work, which has caused many inconveniences to the protection of genetic resources (Zhou, 2016). Next, China's current law is not perfect: China's legislation on the protection of genetic resources does not make specific provisions on the registration of genetic resources; Source disclosure is not required in applications for new varieties that rely on genetic resources in the related regulation; the interpretation of the current law can only solve the problem of access to genetic resources, but cannot solve the problem of benefit sharing ( $\mathrm{Du}, 2007 ; \mathrm{Li}, 2016)$; even though China has already initiated legislative drafting of the Regulations on the Management of Access to Genetic Resources and Benefit-sharing, but the legislative process has been slow (Zhou, 2016). The author holds that genetic resources protection should be included in the framework of intellectual property protection, supplemented by other systems to improve. Nevertheless, few articles have discussed the protection of genetic resources from the perspective of intellectual property protection in China. This paper reviewed current practices and policies on intellectual property, and access to genetic resources, in an attempt to better understand the nature of genetic resources and the difficulties of intellectual property protection, expound theoretical framework of genetic resource protection, so as to propose corresponding improvement suggestions under the context of China.

\section{The Nature of Genetic Resource}

"Genetic resource" means any genetic material of a biological resource contain- 
ing genetic information having actual or potential value for humanity and includes derivatives, fauna and flora of terrestrial, aquatic and any other origin which may be used by the holder to obtain specific practical outputs in any field of human activity or derivative (World Intellectual Property Organization, 2016). The European Patent Office (EPO) emphasized that the concept of genetic resources is closely related to biotechnology genetic resources. Biotechnology is the use of biological processes, biological organisms or systems to create products designed to improve the quality of human life (EPO, 2018). According to China's Patent Law Regulations and CBD, the legal definition of genetic resources refers to "materials with genetic functional units and actual or potential value (Standing Committee of the National People's Congress, 1992)." This definition embraces two elements: firstly, genetic resources contain genetic functional units that can stably transfer traits to the next generation; secondly, it must have actual or potential value in actual production and life. Specifically, genetic resources have 3 main characteristics: complexity, non-renewability and unbalanced distribution, and high-value and potential of value.

To begin with, in terms of the complexity of genetic resources, genetic resources are a combination of tangible materials and intangible information. Genetic information contained in genetic resources exists in the form of a password (gene sequence). Access to genetic information is not necessarily based on the acquisition of biological carriers, but only a small number of samples, which is the value of genetic resources for intellectual property. The genetic information contained can be. In general, the scientific research results can be gained as long as the genetic sequence of the organism, that is, the life code of the ATCG4 type base arrangement, is obtained. This feature reveals the association between genetic resources and intellectual property.

Next, genetic resources are non-renewable and unbalanced distributed. The carrier of genetic information is a biological material with an extremely sophisticated production and replication system. "When a species is disappearing from the earth, if the genetic information of the species is not extracted in advance, the genetic resource will be permanently lost." ( $\mathrm{Du}, 2007)$ UNDP (United Nations Development Programme) reported "more than 90\% of the world's biological species are distributed in Africa, Asia, and South America (Tao, 1996)". The distribution in the world shows that fewer genetic resources exist in technologically advanced regions, while more in technologically backward regions. The domestic animal, artificially cultivated plants also contains the excellent traits that the smart and hard-working Chinese people have selected for thousands of years, which is of high genetic value. However, in the past 100 years, "China's genetic resources have been plundered seriously, which has harmed national interests (Wu, 2016b).”

With regard to the high-value and potential of value of genetic resources, it is related to human's source of energy and daily treatment of diseases or health care products. "More than half of the world's drugs are derived from plants or 
plant compounds (Xu, 2015).” Next, genetic resource providers and users have information asymmetry. Genetic resources users can use advanced technology to obtain more in-depth information, thereby deliberately concealing the economic value of the resource, obtaining genetic resources at a relatively low price, and applying for research and development to apply for patents to win high profits. If the patent based on the genetic resource has a wide range of influences and high applicability, the provider of genetic resources cannot obtain the benefit and also need to pay high fees for the application of the patent. This is obviously unfair.

\section{Obstacles in Protecting Genetic Resources under the Intellectual Property System}

As it mentioned above, as long as a part of the tissue, or even a cell, on the biological material can extract the genetic information contained in the entire biological material. Therefore, it is costly and inefficient to prevent biopiracy from obtaining genetic information from the source. However, biopiracy can benefit from the consumer market by producing practical products for the development from genetic resources. Their research and development results will be protected by patent rights and new plant variety rights which are monopoly interests. The resource can be defensively protected during the intellectual property application review process.

There are two main obstacles in protecting genetic resources under the intellectual property system. Firstly, the benefits of developing countries and developed countries are different. Developed countries with advanced technology and poor domestic resources are of course willing to obtain the genetic resources of other countries at a low cost to meet the further development of their own national technology. Developing countries with backward biotechnology and abundant domestic resources hope that developed countries can share their benefits. However, developed countries have a dominant position in the negotiation of intellectual property protection of genetic resources. In February 2013, the World Intellectual Property Organization discussed the issue of protecting genetic resources. WIPO described the intellectual property concepts in the guide involved in protecting traditional knowledge and traditional cultural expressions and outlines existing international, regional and national protection systems. The guide then went on to provide guidance on the issues that countries, and indigenous peoples and local communities, need to address when considering the role that intellectual property can play in protecting genetic resources from misappropriation, and in generating and equitably sharing benefits from their commercialization (World Intellectual Property Organization, 2013).

Secondly, lack of international restraint mechanism also makes the protection more difficulty. In 1992, under the efforts of many developing countries, CBD adopted by the United Nations Environment Programme established the state's sovereignty over genetic resources. The subsequent adoption of the Nagoya 
Agreement and the Bonn Guidelines further refined the protection and benefit-sharing of genetic resources (Secretariat of the Convention on Biological Diversity, 1992). It also identified the three major objectives of the Convention: "protecting biodiversity, sustaining the use of its components, and sharing benefits arising from genetic resources (Standing Committee of the National People's Congress, 1992)."

Although the international conventions such as the CBD have been established, the above international conventions still lack binding mechanisms and mandatory obligations. Some developed countries have not joined the convention. Although developing countries can protect their own genetic resources through domestic legislation, this can only be within the sovereignty of the country. If developed countries access genetic resources from genetic resources providers, they may not be able to apply for patents and new plant varieties in countries providing genetic resources, but they can still apply in other countries. Taking China as an example, China's 2008 Patent Law stipulates the disclosure obligations of patent applications for genetic resources and the consequences of violations (Standing Committee of the National People's Congress, 2009). However, if a research institution in a country steals patents for genetic resources in China, although the undisclosed obligation does not indicate the source of genetic resources, and it is only impossible to obtain patents in China, it can still apply to other countries.

\section{Theoretical Framework for the Protection of Genetic Resources}

\subsection{Property Rights Attribution System}

With the awakening of the awareness of genetic resources protection in various countries, national sovereignty was confirmed in the 1992 CBD Agreement, and the issue of the attribution of genetic resources entered the discussion: genetic resources belong to the community, private or state. The essence of the issue of the ownership of genetic resources lies in the question of who owns the benefits from the development of genetic resources, and who owns the right of genetic resources custody and regulation.

For community property rights, in the process of human beings adapting to the natural transformation of nature, human beings have made outstanding contributions to the preservation, maintenance and development of genetic resources by community. "Community property rights are the ownership of the property rights of genetic resources in a sovereign country that contributes to the preservation, maintenance and development of genetic resources. The residents of the community exercise their rights and obligations to genetic resources (Zhao, 2008)". The subject of community property rights is the community residents, and the object is specific genetic resources. Community residents have the right to control the protection of this genetic resource, have the right to use and allow others to use the genetic resource, and have the right to prevent others 
from using the genetic resource without permission. However, community property rights have its drawbacks. The community may not have relevant professional knowledge and complete negotiating ability. Establishing a community property rights system requires the government to set up special institutions to provide necessary professional guidance for community residents to protect genetic resources, or to manage genetic resources on their behalf. In the UK, the management of natural resource reserves is exercised by government agencies (Hu, 2013). In Australia, the government establishes local protected areas, which are managed by community residents and the government provides professional guidance ( $\mathrm{Li} \& \mathrm{Wu}, 2017)$.

Private property means: "the property rights of genetic resources are completely allocated to individuals. The possession, use, income and disposal of genetic resources are completely autonomous by individual ( $\mathrm{Lu}, 2012)$ ". Under the public ownership of socialist countries, private property rights can be divided into genetic resources through land use rights. Private property rights are the result of the complete privatization of genetic resources. Individuals can be given more explicit rights and obligations on an individual basis. Private property rights help to more clearly define the rights and responsibilities of genetic resources and reduce some unnecessary property rights disputes, thereby improving market utilization efficiency and reducing transaction costs. However, community property rights system and the ethical basis of community property rights are derived from the long-term preservation of genetic resources by community ancestors. It is obviously unfair to obtain the property rights of genetic resources through the ownership or use of land, rather than based on the maintenance and development of genetic resources. Due to the insufficient professional of private property rights, the government need set up a special department to provide assistance.

National property rights mean that the state has complete access to genetic resources and manages genetic resources through a range of systems. This model is proposed to solve the problem of the above-mentioned genetic resources belonging to the community or private ownership, that is, the information asymmetry between the private or community owners and the demand side of the genetic resources in the negotiations. The problem of national property rights is that the distribution of genetic resources within the country is not balanced, and the contribution of different communities to the protection of genetic resources is not the same. It needs further discussion whether genetic resources are owned by the state for the community residents who contribute more.

\subsection{Genetic Resource Protection Control Model}

There are main 3 control model: public law mode, private law mode, and self-regulatory mode. Firstly, public law mode means that "the state adopts legislation to regulate and control the access and benefit sharing of genetic resources (Zhang, 2012).” Public law controls are generally applied in the devel- 
oping countries with less developed biotechnology and rich biological genetic resources. These countries are also the most seriously devastated by biological plunder. Public law regulation can strengthen the dominant position of state power in the process of protection of genetic resources, more effectively protect the interests of genetic resource providers, and contribute to achieving fairness and rationality in biological development and utilization research.

Private law mode is that "a country does not have specific legislative or special provisions for access and benefit-sharing of genetic resources (Liu, 2010).” Countries adopting this model only benefit from the access to genetic resources through the current property rights and contract law systems. The behavior of the subject is regulated, and its purpose is to autonomy. The model is based on the private property rights system, emphasizing autonomy of meaning, with high flexibility and efficiency, which can simplify the transaction process and reduce transaction costs. At the same time, stakeholders can establish a personalized contract through the autonomy of will to constrain the rights and obligations of both parties, so that the contract can be more flexibly adapted to the needs without having to comply with the regulations enacted by the state. However, the ideal private law model is based on equality between the two parties. The reality is that both sides may be extremely unequal in terms of biotechnology level and economic strength. Under such conditions, there will undoubtedly be fraudulent coercion. It is difficult to guarantee the goal of fair benefit sharing.

Self-regulatory mode means that "national protection of genetic resources does not rely on the development of special regulations and regulations, nor on the use of the existing private law framework, but encourages stakeholders to develop voluntary industry codes of conduct, and to achieve the goal of adjustment and regulation of benefit-sharing genetic resources through self-constraining (Qin, 2007)". Genetic resource providers can protect their rights and interests and obtain corresponding benefits through a self-regulatory model when the legal framework is imperfect. This model also avoids complicated procedures under public law control, and a lot of inconvenience due to the rigid rules of the industry. In addition, the industry code of conduct in the self-regulatory mode can make stakeholders more aware of their moral responsibility to maintain their good public image. However, when the stakeholders do not comply with the industry standards for their own interests, the law cannot provide relevant guarantees.

\subsection{Property Registration System}

Since there are practical difficulties in recognizing the property rights of genetic resources, and only a part of biological entities is needed to obtain all the genetic information of genetic resources, it is easy for anyone to obtain genetic resources. The property rights registration system is "to provide management and comprehensive services for the protection of genetic resources through the establishment of a genetic resource database, to assist in the acquisition, collection, 
analysis, management and service of property information and biological information (Luo, 2007)." The registration of the property rights of genetic resources and the information of genetic resources is used to publicize the effect of public trust, to clarify the ownership of genetic resources, and to reduce disputes caused by the theft of genetic resources. At the same time, the gene resource database can also be regarded as a platform for cooperation and exchange. The property rights person of genetic resources and the demand side of genetic resources can cooperate and exchange through this platform, which improves the utilization efficiency of genetic resources and reduces transaction costs (Zhang \& Zhou, 2013).

\subsection{Prior Informed Consent System}

The Convention stipulates that the prior informed consent system mainly consists of three key points: "prior", "informed" and "consent" (Standing Committee of the National People's Congress, 1992). "Prior" means that the demand side of the genetic resource should first obtain the consent of the provider of the genetic resource to obtain the genetic resource instead of the opposite (Santos, 2010). "Informed" means that the instructions made by the demand side when applying for access to genetic resources should be as sufficient as possible, so that the owner of the genetic resources can understand the comprehensive information of access to genetic resources and development and utilization (Santos, 2010). "Consent" is a prerequisite for the legal acquisition of genetic resources by the demand side of genetic resources. No matter what kind of genetic property ownership system is adopted by a country, community property rights, private property rights or state property rights, the demand side must obtain both the property owner and the state administrative authority's dual license (Gepts, 2004). The genetic resource provider and the national administrative authority may refuse the genetic resource demander's application for access to genetic resources due to the contrary to national interests, social interests, and the interests of the property rights holders of genetic resources. In this process, the administrative authority plays the role of examiner, examining whether the property right transaction of genetic resources will endanger the national and social interests, and whether it will lead to the negative impact of the economic environment.

\subsection{Source Disclosure System}

"Source disclosure system is a supporting and safeguarding system for the prior informed consent system and is one of the defensive protection systems for genetic resources" (Zhang, 2015). It is mainly used in the process of applying for intellectual property rights to prevent the acquisition of genetic resources based on theft or other illegal means. The system requires applicants to make necessary statements about the source of the resources they use when it comes to the use of genetic resources, including the original source and source of genetic resources, 
the owner of genetic resources and the relevant evidence that the administration prior informed and consent. Among them, the original source refers to the direct acquisition of biological materials, and the derived source refers to the acquisition of genetic resources through the genetic database (Aguilar, 2001). The competent authorities of intellectual property rights need to review the disclosure of the source. If the application for intellectual property protection is improperly applied, it shall be rejected. If the intellectual property rights have been granted, it shall be revoked. In fact, the countries that have different national conditions hold different positions when applying for intellectual property protection. The developed countries have advanced biotechnology. It is hoped that domestic enterprises and institutions can develop research and apply for intellectual property rights through low-cost access to genetic resources of other countries, and of course they are reluctant to introduce mandatory source disclosure. However, due to the slow progress of biotechnology in developing countries, the loss of genetic resources in the country is serious. Without usage fees from developed countries, the developing countries also have to pay a large amount of usage fees due to the intellectual property rights of the developed countries (Maskus, 2001; Wu, 2016a). Hence, a mandatory source disclosure system is hoped to be introduced.

To sum up, national governments, private companies, non-governmental organizations, and research institutions need attempt to overcome, with varying degrees of success, the obstacles discussed in Chapter 3. One of the main problems in regulating access to genetic resources lies in the tension between property and use rights over land, which may be private or community-based, versus the sovereign rights of countries over the genetic resources that the land contains. This chapter also provided 3 genetic resource protection control model: public law mode, private law mode, and self-regulatory mode. In addition, property registration system, prior informed consent system, and information disclosure system are feasible and necessary approaches.

\section{The Improvement Suggestions of Genetic Resources Protection in China}

\subsection{The Choice of China's Genetic Resources Protection Control Mode}

China is a provider of genetic resources. Before the breakthrough in biotechnology, the model of genetic resource protection should be based on the public law model and strengthen the country's dominant position. Legislation of genetic resources protection determines the minimum obligations that genetic resource demanders should follow in access and benefit-sharing activities for genetic resources. This will increase the control of the government and the state, and help reduce the adverse effects of the gap in biotechnology ( $\mathrm{Wu}, 2016 \mathrm{a})$.

Of course, the choice of the regulatory mode does not mean that only one mode of control is chosen. Instead, China can learn the advantages of multiple 
modes and cooperate with each other to accomplish the task of protecting genetic resources with the highest efficiency. For example, China can absorb the advantages of the efficiency and flexibility of the private law model. Both parties to the genetic resources transaction can conduct free consultations within the framework of the minimum standards of public law regulation, so that access and benefit-sharing arrangements for genetic resources are more in line with the actual needs of both the supply and demand sides of genetic resources, simplifying transaction procedures and reducing transaction costs (Zhang, 2012). Self-regulatory models can also be encouraged. Genetic resources suppliers can generate self-regulatory guidelines on access and benefit-sharing of genetic resources through industry organization to restrict the behavior of all parties (Yan \& Wu, 2012). The self-regulatory guidelines cannot be lower than that required by the public law regulatory framework. This will not only reduce the burden on the country, but also promote self-regulatory in the industry.

In short, considering to the national conditions that China is rich in genetic resources and socialist market economic system, China's choice of genetic resource protection control mode can be a comprehensive control mode, based on public law control, supplemented by private law control and self-regulation control, to make up for the inadequacy of public law regulation, such as rigidity, inefficiency and high cost.

\subsection{Determination of China's Genetic Resources Protection and Control System}

As mentioned above, China's protection of genetic resources is regulated by various departments, which leads to the lack of adequate communication and coordination between departments. It is not conducive to the promotion and development of the overall work. With the continuous growth of the demand for genetic resources in China's scientific and technological production, as well as the loss of genetic resources, the competent authority for the protection of domestic genetic resources should be determined according to the actual situation and basic national conditions.

The improvement of China's protection control should be directed towards coordinated control and single control. Coordinated control refers to the establishment of an inter-agency, cross-sectoral coordination department based on existing separate controls. It does not give substantive powers to inter-agency and inter-departmental coordination agencies. The agencies are mainly responsible for unifying leadership, coordinating various agencies and departments, increasing communication and cooperation, and completing China's genetic resources protection work more closely (Qiao, 2011). In this model, it is only necessary to add a coordination department between the departments without having to change the original control rights of each department to the genetic resources within the jurisdiction of the department. In this way, it is not necessary to change the existing control pattern of genetic resources, but also help to improve the coordination among various departments, in line with the actual 
situation in China at present. It will strengthen the coordination of protection of genetic resources in the most stable and economical way, and make up for the drawback of the incomplete protection coverage ( $\mathrm{Hu}, 2013)$. As for the single control, it can be seen as a further improvement than the coordinated control. However, in the current situation in China, it is not suitable to put things right once and for all. It is possible to establish a coordinated control mode as conduct exploration and practice, and then further turn to a single control until the conditions are mature.

\subsection{Suggestions on the Legislative form of Genetic Resources Protection in China}

Article 9 of the Constitution of the People's Republic of China states: "the state ensures the rational use of natural resources and protects rare animals and plants. Appropriation or damaging of natural resources by any organization or individual by whatever means is prohibited (Wei, 2014)." This is a constitutional regulation on the protection of genetic resources. Other regulations on the protection of genetic resources are distributed in many laws and regulations such as Animal Husbandry Law, Seed Law, Fisheries Law, and Wild Animal Conservation Law.

In order to ensure the effective implementation of the Nagoya Protocol (NP), all contracting governments need to establish a national institutional framework that is in line with the NP, especially the construction of the legal system (Wu, 2016a). From the perspective of foreign legislative practice, the special law for the protection of genetic resources has long been the trend of the world. At present, 60 countries have legal measures to manage access and benefit sharing of genetic resources. Countries with rich biological genetic resources such as India, Brazil, and Australia have adopted national legislation ( $\mathrm{Wu}, 2016 \mathrm{a})$. The advantage of developing a special law is that the law only targets a specific object of genetic resources, which is highly targeted; the coverage can be applied to all types of genetic resources, filling the gaps that cannot be fully covered by the current legislative form (Zhang, 2012). From the legislative level, it is more appropriate for the State Council to issue administrative regulations. Because the administrative law is more effective than the departmental regulations, avoiding the conflicts of new powers triggered by the departments to refines the regulations through departmental regulations. Compared with the law, the legislative difficulty and legislative cost of administrative regulations are relatively low, and the legislative procedure is relatively convenient, which will not cause waste of legislative resources (Qin, 2007). China can first introduce the principled provisions through legislation, then gradually improve and refine it, and explain the problems arising in the implementation of the law by means of legal guidance.

\subsection{Improvement of the Legal System for the Protection of Genetic Resources in China}

Firstly, further confirm the property rights through legislation. Although CBD 
stipulates the principle of national sovereignty, it only determines the status of genetic resources in international law, which fails to give an answer to the question of whether the country should obtain the ownership of genetic resources (Glowka, 1998). Article 17 of Wild Animal Conservation Law of the People's Republic of China points out: "The competent department of wild animal conservation of the State Council shall, in conjunction with the relevant departments of the State Council, conduct planning on the conservation and utilization of genetic resources of wild animals, establish a national gene bank of genetic resources of wild animals (Standing Committee of the National People's Congress, 2016)." Article 12 of Animal Husbandry Law of the People's Republic of China prescribed: "The stockbreeding and veterinary administrative department of the State Council shall, according to the distribution of the livestock and poultry genetic resources, formulate and announce the national protection list of livestock and poultry genetic resources, and lay the emphasis on the protection of the valuable, rare and endangered livestock and poultry genetic resources originated from China (Standing Committee of the National People's Congress, 2007)". It can be seen that China has already established genetic resources gene database. However, China's current laws do not make specific provisions on the registration of genetic resources, which leads to the lack of legal basis for the registration of genetic resources in practice.

The author believed that the property rights of genetic resources should be based on national property rights, strengthen national control, reduce the loss of genetic resources, and occupy a favorable position in the international exchange of such resources. Additionally, taking into account the outstanding contribution of community collective residents to the preservation, maintenance and development of genetic resources, the benefits arising from the utilization of genetic resources should be more rational distributed to encourage community residents to actively protect genetic resources (Zhang, 2007). "We can establish a multi-subject of the interest held by genetic resources. In similarity to the separation of 'owner' and 'user' in the geographical indication right, the owner of genetic resources management and disposition is the state, while the possessor, user, and income owner are community organizations and members (Qin, 2006)."

Secondly, the requirements for the prior consent of the application for intellectual property rights are supposed to be described in the legislation (Lu, 2017). Intellectual property, as a way of getting rewards from information, plays a role in the large number of problems arising from the use of biodiversity (Von Lewinskied, 2004). Drawing on the legislative experience of India, any institution or individual who wants to obtain China's genetic resources should have the dual prior consent of the property owner and the competent authority of China (Bisht, Bhat, Lakhanpaul, Latha, Jayan, Biswas, \& Singh, 2005). Additionally, it's suggested to amend the relevant intellectual property law, and review the evidence of prior consent in the examination of the intellectual property application. 
Thirdly, the content of disclosure obligations should be added to the Patent Law and the Plant Variety Protection Regulations by amending laws and regulations (Lu, 2017). China's Patent Law provides a source disclosure system. However, this provision only requires the patent applicant to state the source of the genetic resources, and does not specify procedures such as how to explain and what evidence is required for explanation. "In the current system of protection of new plant varieties, it is impossible to prevent foreign companies and individuals from stealing China's genetic resources to develop new varieties through biotechnology, and then applying to China for the protection of new varieties of plants (Liao, 2012)." There are no clear and specific provisions on the collection or collection of genetic resources, the characteristics of the population, and the detailed description of the genetic resources. There are also no protective provisions for the collection or collection of non-renewable or rare genetic resources, which cannot effectively prevent the devastating consequences of improper or destructive collection and collection of these resources (Dong, 2018).

According to the experience of Brazil, it is necessary to disclose the evidence of the prior informed consent of the property owner and the administrative authority, such as the request for a benefit-sharing agreement ( $\mathrm{Wu}, 2016 \mathrm{a})$. Increasing the disclosure obligations of the demand side of genetic resources will help reduce genetic resources plagiarism. In order to encourage invention and creation and protect the legitimate interests of patent applicants, China should further require disclosure of relevant information such as the source of genetic resources; in order to protect the richness, diversity and continuity of genetic resources, genetic resources demanders should be required to disclose genetic resources collection method. "Strict disclosure scope, standards and procedures in the law provide a legal basis for benefit sharing of genetic resources patents (Dong, 2018)."

At last, the state should set a minimum clause for access and benefit of genetic resources through legislation, listing monetary and non-monetary, short-, medium-, and long-term forms of benefit sharing of genetic resources (Zhang, 2012). On the basis of this minimum clause, the provider of genetic resources and the demand side can negotiate to sign the "Genetic Resources Access and Benefit-sharing Contract (Qin, 2006).” The content of the contract is autonomous, but must meet the basic requirements of the minimum clause, which is the protection provider. At the same time, the provisions on the statutory licensing of intellectual property rights related to genetic resources are supposed to be added, that is, if the intellectual achievement of obtaining intellectual property rights is based on genetic resources or traditional knowledge derived from China, the owner of the intellectual achievement must transfers to or allows it to be used free of charge by the institution established by the competent authority (Liao, 2012).

\section{Conclusion}

Genetic resources are important national strategic resources. China is a provider 
of genetic resources. The existing legal and institutional systems have insufficient protection of genetic resources. The non-renewability and high-value of genetic resources determine the necessity of the state for its protection; its complexity determines the way in which intellectual property is applied for protection; its potential of value determines that the state should play a leading role. At present, the main difficulties in protecting this kind of resources are the imperfect legislation, the unclear protection system and the incomplete international restraint mechanism. This paper believes that the property rights system of genetic resources should be based on state property rights and supplemented by community property rights; the control model should be based on the public law model, supplemented by the private law model and the self-regulation model (Liu, 2017); the control system should gradually transition from the current control of each department to a single departmental control; the legislative form of genetic resources protection should be changed from the current multiple departmental laws to specific legislation for such resources, and the existing protection loopholes should be filled in special legislation to refine the protection steps.

\section{Conflicts of Interest}

The author declares no conflicts of interest regarding the publication of this paper.

\section{References}

Aguilar, G. (2001). Access to Genetic Resources and Protection of Traditional Knowledge in the Territories of Indigenous Peoples. Environmental Science \& Policy, 4, 241-256. https://doi.org/10.1016/S1462-9011(01)00028-4

Bisht, I. S., Bhat, K. V., Lakhanpaul, S., Latha, M., Jayan, P. K., Biswas, B., \& Singh, A. K. (2005). Diversity and Genetic Resources of Wild Vigna Species in India. Genetic Resources and Crop Evolution, 52, 53-68. https://doi.org/10.1007/s10722-005-0286-0

Dong, Y. (2018). The Protection of Genetic Resources Right in the Perspective of Interests. Intellectual Property, 4, 78-82+96.

Du, L. (2007). On systems of Biological Genetic Resources Protection in Developing Countries. Master's Thesis, Beijing: China University of Political Science and Law.

European Patent Office (2018). Biotechnology Patents at EPO. http://www.epo.org/news-issues/issues/biotechnology-patents.html

Gepts, P. (2004). Who Owns Biodiversity, and How Should the Owners Be Compensated? Plant Physiology, 134, 1295-1307. https://doi.org/10.1104/pp.103.038885

Glowka, L. (1998). A Guide to Designing Legal Framework to Deternine Access to Genetic Resources. Bonn, Germany: IUCN Environment Law Centre.

$\mathrm{Hu}$, Z. (2013). Management and Utilization of Human Genetic Resources in the UK. Global Science and Technology Economics Outlook, 28, 16-20.

Li, Y. (2016). The Thesis on the Regime of Access and Benefit-Sharing and Intellectual Property. Hebei Law Science, 34, 51-59.

Li, Y., \& Wu, J. (2017). Status, Cases and Enlightenment of Australian Legal System for Access and Benefit Sharing of Biological Genetic Resources. Journal of Agricultural 
Resources and Environment, 34, 24-29.

Liao, X. (2012). Thoughts on Constructing the System of Access and Benefit Sharing of Genetic Resources in China. Jiangxi Social Sciences, 32, 163-167.

Liu, F. (2010). Comparison of Genetic Resources Access and Benefit Sharing Systems in Europe and America. Economic Forum, 1, 213-215.

Liu, X. (2017). On the Improvement of the Legal System of Access and Benefit Sharing of Genetic Resources in China. Legal System and Economy, 12, 58-59+70.

Lu, B. (2017). A Comparative Study on Sino-US Patent Protection System of Animals and Plants. World Agriculture, 7, 87-89+244.

Lu, X. (2012). Study on the Allocation of Property Rights of Forestry Plant Genetic Resources. Fujian Forum, 4, 27-30.

Luo, S. (2007). Benefit Sharing and Intellectual Property Protection of Genetic Resources. Master's Thesis, Shanghai: Shanghai Jiao Tong University.

Maskus, K. E. (2001). Intellectual Property Challenges for Developing Countries: An Economic Perspective. University of Illinois Law Review, 4, 457-474.

OECD (1996). Intellectual Property, Technology Transfer and Genetic Resources. http://www.oecd.org/science/emerging-tech/1947170.pdf

Qiao, X. (2011). Patent Protection System of Genetic Resources in China. Master's Thesis, Wuhan: Huazhong Normal University.

Qin, T. (2006). Research on Legal Issues of Access to Genetic Resources and Benefit-Sharing. Wuhan: Wuhan University Press.

Qin, T. (2007). The Regulatory Model of Access and Benefit-Sharing of Genetic Resources in the European Union and Its Member States-Also on the Enlightenment to China. Science \& Technology and Law, 2, 84-90.

Santos, L. A. (2010). Genetic Research in Native Communities. Progress in Community Health Partnerships, 2, 321-327. https://doi.org/10.1353/cpr.0.0046

Secretariat of the Convention on Biological Diversity (1992). Bonn Guidelines on Access to Genetic Resources and Fair and Equitable Sharing of the Benefits Arising out of Their Utilization. https://www.cbd.int/doc/publications/cbd-bonn-gdls-en.pdf

Standing Committee of the National People's Congress (1992). Convention on Biological Diversity.

Standing Committee of the National People's Congress (2007). Animal Husbandry Law of the People's Republic of China (2007 Revision).

http://www.lawinfochina.com/display.aspx?lib=law\&id=4865\&CGid

Standing Committee of the National People's Congress (2009). Patent Law of the People's Republic of China.

Standing Committee of the National People's Congress (2016). Wild Animal Conservation Law of the People's Republic of China (2016 Revision).

http://en.pkulaw.cn/display.aspx?id=22418\&lib=law\&SearchKeyword=\&SearchCKeyw ord

Tao, X. (1996). A Brief Discussion on Environmental Colonialism in Contemporary International Relations. Journal of School of International Relations, 3, 8-13.

Von Lewinskied, S. (2004). Indigenous Heritage and Intellectual Property: Genetic Resources, Traditional Knowledge and Folklore. Netherlands: Kluwer Law International B.V.

Wei, L. (2014). Legal Protection of Biological Genetic Resources from the Perspective of International Human Rights. Journal of Jilin Teachers Institute of Engineering and 
Technology, 30, 11-14.

World Intellectual Property Organization (2013). Intellectual Property, Traditional Knowledge and Traditional Cultural Expressions/Folklore: A Guide for Countries in Transition. https://www.wipo.int/edocs/pubdocs/en/wipo_pub_transition_9.pdf

World Intellectual Property Organization (2016). The Protection of Traditional Knowledge, Genetic Resources and Expressions of Folklore Act. https://www.wipo.int/tk/en/databases/tklaws/articles/article_0082.html

$\mathrm{Wu}$, J. (2016a). International Experience of National Legislation on Access to Genetic Resources and Benefit Sharing. Environmental Protection, 44, 71-74.

Wu, J. (2016b). The Protection of Intellectual Property Rights Related to Biological Genetic Resources and Traditional Knowledge in China Needs to Be Strengthened. World Environment, 48, 16-18.

Wu, J., Xue, D., Zhao, F., \& Wang, Y. (2013). Impacts of the Nagoya Protocol on Access to Plant Genetic Resources and Benefit Sharing in China. Biodiversity Science, 21, 758-764. https://doi.org/10.3724/SP.J.1003.2013.07153

$\mathrm{Xu}$, S. (2015). Discussion on Domestic Legal Regulation of Biopiracy. Environmental Protection and Circular Economy, 35, 4-9.

Yan, H., \& Wu, Q. (2012). International Legislation on Benefit Sharing of Biological Genetic Resources and Construction of Chinese System. World Agriculture, 8, 45-49.

Zhang, C., \& Zhou, Y. (2013). Intellectual Property Rights on Plant Genetic Resources: Perspective from Economics. Chinese Journal of Population Resources and Environment, 10, 59-63. https://doi.org/10.1080/10042857.2012.10685110

Zhang, Q. (2015). Study on the Disclosure System of the Source of Genetic Resources in the Patent Law. Master's Thesis, Shanghai: East China University of Politics and Law.

Zhang, X. (2007). On the Access and Benefit-Sharing of Chinese Genetic Resources. Science of Law: Journal of Northwest University of Political Science and Law, 1, 142-157.

Zhang, X. (2012). The Research of Law issues Access to and Benefit-Sharing of Genetics. Master's Thesis, Changsha: Central South University of Forestry and Technology.

Zhao, J. (2008). Study on the Basic Issues of Community Knowledge Right in the Protection of Biological and Genetic Resources. Lanzhou Academic Journal, 7, 115-119.

Zhou, Y. (2016). Research on Intellectual Property Protection of Biological Genetic Resources. Master's Thesis, Harbin: Northeast Forestry University. 